\title{
Soldiers of Song: The Dumbells and Other Canadian Concert Parties of the First World War.
}

By Jason Wilson. Waterloo: Wilfrid Laurier University Press, 2012. 239 pp. ISBN 978-1-55458844-2.

Jason Wilson, an accomplished musician who has authored three previous books on Canadian history and culture, has written an outstanding book on the musical entertainment for Canadian soldiers during the First World War. Soldiers of Song discusses the Canadian "concert parties" that performed during and after the war, with a focus primarily on the most wellknown show, the Dumbells.

Concert parties were a form of military-sanctioned variety entertainment organized for the purpose of raising troop morale. They rapidly evolved from quasi-improvised performances by front-line soldiers on leave to more established arrangements where the members were fulltime performers. Although concert parties have been discussed previously in the literature, especially the Dumbells, this is the first time that the subject has been given such a detailed treatment. I was impressed by the author's ability to balance an historical approach with cultural analysis. This is in contrast to earlier works on concert parties, which are more descriptive. The author's extensive use of primary materials also makes the book a useful historical source on early-twentieth-century Canadian popular music.

The book is divided into six thematic chapters, including the origins and development of concert parties in the war years, the postwar success of the Dumbells, and their later influence on Canadian culture, especially comedy. This organization works well as the themes are discussed in detail while the narrative draws the reader into the story.

Wilson reviews British and American influences on Canadian concert parties, which is helpful to readers not familiar with these traditions. At the same time, he demonstrates that Canadian wartime entertainment took on its own distinct character as the war progressed. In contrast to the British entertainments, the Dumbells and other Canadian parties reflected the Canadian experience of trench warfare. There were wry "in" jokes (the hopelessly inadequate Ross rifle, for example) that only a Canadian soldier could understand.

Wilson argues that this irreverent style of humour had a lasting impact, notably on the art of such famous comedians as Wayne and Shuster and Lorne Michaels. He also convincingly demonstrates the profound influence that the Dumbells had both at home and abroad. The first Canadian revue to have a Broadway hit (Biff, Bing, Bang, 1921), the troupe also racked up impressive sheet music and record sales.

Another noteworthy theme is the analysis of the role of female impersonators in the shows. Intriguingly, Wilson suggests that members of the audience were duped into believing there 
were women on stage. He also asserts that the impersonators were one of the Dumbells' biggest draws. Although Wilson references gender theorists such as Judith Butler, this is a topic that could have been explored more.

Nevertheless, overall, Soldiers of Song is a valuable and insightful survey of wartime entertainment that also sheds light on Canadian music theatre of the early twentieth century. Reproductions of photographs of performers and performances are interspersed throughout, and there is an extensive list of sources and acknowledgements. Completing the presentation are nine appendices detailing the personalities, performances, and publication histories of the most prominent Canadian concert parties.

Sean Luyk

University of Alberta 